\title{
CHARACTERIZATION AND EXTRAPOLATION OF A CONCEPTUAL EXPERIMENTAL ACCELERATOR DRIVEN SYSTEM
}

\author{
D. KERDRAON (1), A. BILlEBAUD (1), R. BRISSOT (1), \\ B. CARLUEC (2), S. DAVID (3), D. HEUER (1), C. LE BRUN (1), \\ E. LIATARD (1), J-M. LOISEAUX (1), O. MÉPLAN (1), E. MERLE (1), \\ H. NIFENECKER (1), D. VERRIER (2)
}

(1) Institut des Sciences Nucléaires, IN2P3-CNRS and Université Joseph Fourier, 53, Avenue des Martyrs F-38026 Grenoble CEDEX, France

(2) Framatome ANP, 10, rue Juliette Récamier F-69006 Lyon CEDEX, France

(3) Institut de Physique Nucléaire d'Orsay, IN2P3-CNRS and Université Paris XI, BP 1, F-91406 Orsay CEDEX, France

\begin{abstract}
This paper deals with the neutronic Monte Carlo simulations in view of an eXperimental Accelerator Driven System (XADS) optimization and characterization. With this aim, the quite realistic concept of XADS chosen for our investigations, comes from the preliminary studies done by Framatome ANP. First, we simulate this basic concept with different fuels and characterize the time evolution of the conceivable fuels, especially with minor actinides. Secondly, we consider the neutronic parameters in view of an extrapolation of the XADS toward a large ADS. We also consider some alternative solutions to reduce the flux peak in the first assemblies around the spallation target of a large ADS and consequently to improve the shape factor and the efficiency of the core. Finally, we focus on the generation of ${ }^{233} \mathrm{U}$ based on a plutonium and minor actinide fuel associated to thorium oxide to start power Molten Salt Reactors (MSR) and to accelerate the transition toward a ${ }^{232} \mathrm{Th} /{ }^{233} \mathrm{U}$ cycle which offers an interesting option for nuclear waste reduction and nuclear energy production during many centuries.
\end{abstract}

Keywords

ADS Transmutation Nuclear Waste Thorium 


\section{INTRODUCTION}

Accelerator Driven Systems (ADS), based on a proton accelerator and a sub-critical core coupled with a spallation target, offer advantages in terms of flexibility in using exotic fuels, allowing operation with reactivity variations and in term of intrinsic safety. Among the possible applications is the reduction of nuclear waste radiotoxicity before repository closure. With this aim, many studies carried out on the Accelerator Driven Systems (ADS) should lead to the definition of an experimental plant which would federate the different works in progress [1] [2]. First, we present and simulate with the MCNPX code [3] the concept of eXperimental Accelerator Driven System (XADS) based on a design made by Framatome ANP [4]. Also, we consider the time evolution of the main fuels which could be reasonably used for the demonstration phases. The neutronic parameters of the reactor, concerning minor actinide transmutation, are examined. Also, we identify some neutronic differences between an experimental and a large ADS concerning the infinite multiplication coefficient, the shape factor and the level of flux so as to extend the demonstrator concept to a large reactor prototype. We propose geometric solutions to keep the radial shape factor of a large ADS acceptable. In the last part, beyond the XADS scope, we examine the possible transition towards an uranium/thorium cycle based on Molten Salt Reactors using a large ADS in order to generate the required ${ }^{233} \mathrm{U}^{2}{ }^{232} \mathrm{Th}$ fuel mixture to start Molten Salt Reactors power reactor.

\section{XADS SIMULATIONS}

\subsection{The XADS geometrical parameters}

The geometrical parameters of the XADS, shown in figure 1, have been described with a high level of accuracy in our simulations carried out using the MCNPX code. The computational setup includes the spallation target with the eutectic lead-bismuth liquid, a multiplication zone with ninety hexagonal heterogeneous assemblies (Hexagonal Tube) and a reflector. For the reference phase, the basic fuel is composed of a Mixed Oxide (MOX) of uranium and plutonium with a variable concentration of plutonium but less than 30 percent for safety reasons. The plutonium is provided by the irradiated fuel of a 900 MWe PWR with a specific burn-up of 33 GigaWatt day per metric ton $(\mathrm{GWd} / \mathrm{t})$ and the isotopic vector with the enrichment $(e)$ is given in table 1.

Table 1: Isotopic vector with the enrichment $(e)$ in the reference MOX fuel $(0 \leq e \leq 0.3)$.

\begin{tabular}{|c|c|}
\hline Isotope & $(\%)$ \\
\hline${ }^{235} \mathrm{U}$ & $0.72 \times(1-e)$ \\
\hline${ }^{238} \mathrm{U}$ & $99.28 \times(1-e)$ \\
\hline${ }^{238} \mathrm{Pu}$ & $1.97 \times e$ \\
\hline${ }^{239} \mathrm{Pu}$ & $53.31 \times e$ \\
\hline${ }^{240} \mathrm{Pu}$ & $25.67 \times e$ \\
\hline${ }^{241} \mathrm{Pu}$ & $9.87 \times e$ \\
\hline${ }^{242} \mathrm{Pu}$ & $7.90 \times e$ \\
\hline${ }^{241} \mathrm{Am}$ & $1.28 \times e$ \\
\hline
\end{tabular}

The spallation source is simulated by the LAHET code system [5] integrated in the MCNPX code using the Bertini model [6] of spallation. The arrangement corresponds to a one GeV proton beam incident on a thick eutectic lead-bismuth cylindrical target. We optimize the pitch of the assemblies 


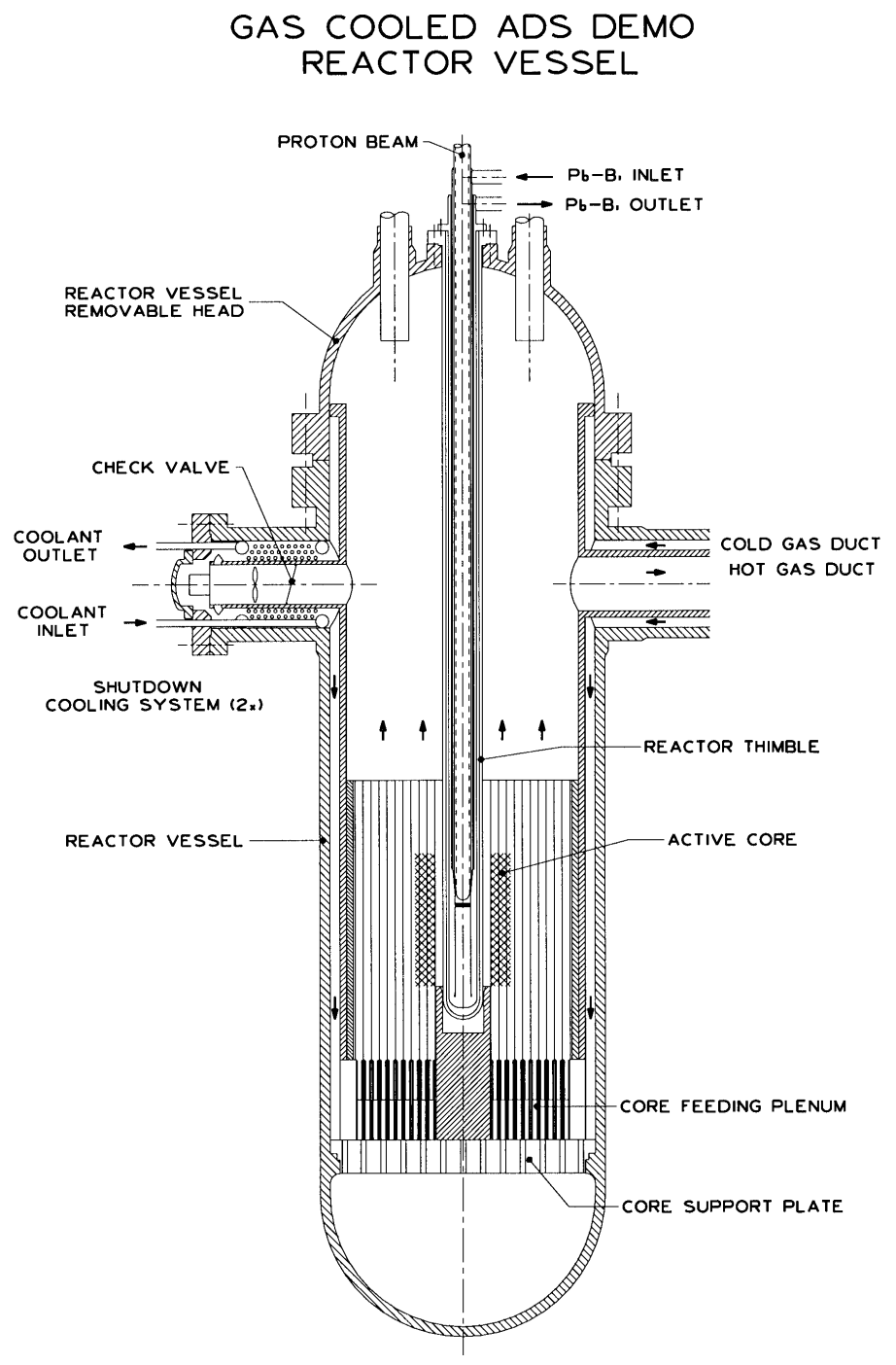

Fig. 1: Cutaway drawing of the XADS designed by Framatome ANP. 
to minimize the unused volume between the spallation module and the hexagonal assemblies. The core has an orthocylindrical shape which confines the neutrons created by the source. The median plan of the active core is centered, vertically, on the maximum intensity of the spallation source. The core is cooled by helium flow pressurized at 60 bars to ensure a fast neutron spectrum. The fact that helium is transparent facilitates in-service inspection and maintenance. The core inlet temperature is $200{ }^{\circ} \mathrm{C}$ to eliminate any risk of spallation target freezing and the core outlet temperature is limited to $450{ }^{\circ} \mathrm{C}$ to reduce the constraints on the structural materials. The proportion of helium in the core is fixed at 50 percent of the internal volume of the assemblies. Inside a hexagonal assembly, the fuel is confined in a pin inside a stainless steel wrapper. Between two pins, a steel wire is inserted in order to maintain the stiffness of the structure and avoid any creep effect on structural materials. The main geometric characteristics of the core are given in table 2 .

Table 2: Main characteristics of the XADS core.

\begin{tabular}{|c|c|}
\hline Plutonium enrichment (\%) & 24. \\
\hline External active core radius (cm) & 85 \\
\hline Internal active core radius (cm) & 29 \\
\hline Height (cm) & 170 \\
\hline Pin radius (cm) & 0.714 \\
\hline Steel wire radius (cm) & 0.274 \\
\hline Number of assemblies & 90 \\
\hline Thermal power (MW) & 100 \\
\hline
\end{tabular}

The one meter thick reflector is composed of several assemblies where the fuel pins are replaced by stainless steel pins. Finally, the volumetric proportions in the core are given in table 3.

Table 3: Main volumetric proportions in the core.

\begin{tabular}{|c|c|}
\hline Coolant (\%) & 47.50 \\
\hline Steel (\%) & 20.10 \\
\hline Fuel (\%) & 32.40 \\
\hline
\end{tabular}

\subsection{Detailed neutron balance}

With such a configuration, the effective multiplication coefficient, noted $\mathrm{k}_{\text {eff }}$, is close to 0.97 . The detailed neutron balance, given in table 4, shows that neutron losses by capture in the steel structures of the reactor are significant. For example, the molybdenum, which amounts to $1.6 \%$ of the steel components, accounts for $14 \%$ of the $(n, \gamma)$ reactions. The lead-bismuth is responsible for $40 \%$ of the $(\mathrm{n}, 2 \mathrm{n})$ reactions which compensate the $(\mathrm{n}, \gamma)$ reactions in the structures of the spallation module. In order to exploit the neutron spallation yield, the spallation module has to maximize neutron transmission to the core. It appears that captures in the spallation module represent only $2.4 \%$ of all the neutronic captures.

\subsection{Time evolution of the XADS fuel}

The time evolution of the fuel is evaluated by coupling the static MCNPX code to the REM (Rules for 
Table 4: Detailed neutron balance in the XADS loaded with a MOX(U/Pu) fuel enriched with 24.1 $\%$ of plutonium with the reference spallation target and a steel reflector (the steel structures in bold characters, the target materials in underlined italic characters and the fuel in regular characters).

\begin{tabular}{|c|c|c|c|c|}
\hline \multicolumn{5}{|c|}{ Neutron balance } \\
\hline & \multirow{2}{*}{$\begin{array}{l}\text { Production } \\
\text { per fission }\end{array}$} & \multicolumn{3}{|c|}{ Disappearance } \\
\hline & & per fission & by iso & ope $(\%)$ \\
\hline Source & 0.083 & - & & - \\
\hline Fission & 2.92 & 1. & $\begin{array}{l}{ }^{235} \mathrm{U} \\
{ }^{238} \mathrm{U} \\
{ }^{238} \mathrm{Pu} \\
{ }^{239} \mathrm{Pu} \\
{ }^{240} \mathrm{Pu} \\
{ }^{241} \mathrm{Pu} \\
{ }^{242} \mathrm{Pu} \\
{ }^{241} \mathrm{Am}\end{array}$ & $\begin{array}{c}2.09 \% \\
9.12 \% \\
1.48 \% \\
62.23 \% \\
7.23 \% \\
15.88 \% \\
1.60 \% \\
0.34 \%\end{array}$ \\
\hline$(n, 2 n)$ & 0.0184 & 0.0092 & $\begin{array}{l}\frac{{ }^{n a t} \mathrm{~Pb}}{\frac{{ }^{209} \mathrm{Bi}}{{ }^{238} \mathrm{U}}} \\
{ }^{{ }^{20 t} \mathbf{F e}}\end{array}$ & $\begin{array}{c}\frac{17 . \%}{23.85 \%} \\
\frac{52.15 \%}{7 . \%}\end{array}$ \\
\hline$(n, \gamma)$ total & - & $\begin{array}{l}1.99 \text { (including } \\
0.048(n, \gamma) \text { in } \\
\text { the spallation } \\
\text { module) }\end{array}$ & $\begin{array}{c}{ }^{16} \mathrm{O} \\
{ }^{n a t} \mathrm{Cr} \\
{ }^{25} \mathrm{Mn} \\
{ }^{n a t} \mathrm{Fe} \\
{ }^{n a t} \mathrm{Ni} \\
{ }^{n a t} \mathrm{Mo} \\
{ }^{\text {nat }} \mathrm{W} \\
{ }^{n a t} \mathrm{~Pb} \\
\frac{{ }^{209} \mathrm{Bi}}{{ }^{235} \mathrm{U}} \\
{ }^{238} \mathrm{U} \\
{ }^{238} \mathrm{Pu} \\
{ }^{239} \mathrm{Pu} \\
{ }^{240} \mathrm{Pu} \\
{ }^{241} \mathrm{Pu} \\
{ }^{242} \mathrm{Pu} \\
{ }^{241} \mathrm{Am}\end{array}$ & $\begin{array}{c}0.40 \% \\
\mathbf{9 . 5 0} \% \\
\mathbf{4 . 2 3} \% \\
\mathbf{1 9 . 0 3} \% \\
\mathbf{8 . 1 5} \% \\
\mathbf{1 3 . 8 8} \% \\
\mathbf{4 . 1 9} \% \\
\mathbf{0 . 1 1 \%} \\
0.14 \% \\
0.48 \% \\
25.0 \% \\
0.44 \% \\
7.65 \% \\
3.82 \% \\
1.24 \% \\
1.06 \% \\
0.65 \%\end{array}$ \\
\hline Neutron leakage & - & 0.022 & & - \\
\hline Total & 3.02 & 3.02 & & - \\
\hline
\end{tabular}


time Evolution with MCNPX) subroutine, developed by Institut des Sciences Nucléaires, which solves the evolution equations (Bateman's equations) using a $4^{\text {th }}$ order Runge-Kutta method. Moreover, the nuclear data processing code NJOY [7] is integrated in the time evolution process to build our modified MCNPX data files from the existing libraries (ENDF-B/VI, JENDL 3.2 and JEF 2.2 libraries) and to take into account the fuel temperature and consequently the Doppler effect. The numerical solving of the evolution equations gives the amount of each nuclide created during the various physical reactions. The thermal power is fixed at $100 \mathrm{MW}$ by controling the proton beam intensity over time. We have considered the main fuels which could be reasonably used for the core:

- During the reliability test phase of the XADS, we have chosen the basic MOX $\left(\mathrm{UO}_{2}-\mathrm{PuO}_{2}\right)$ fuel, described in the previous section.

- The second phase would test new fuels based on minor actinide isotopes extracted from a UOX fuel irradiated in a 900 MWe PWR with a specific burn-up of $33 \mathrm{GWd} / \mathrm{t}$ and cooled for 36 years (two ${ }^{244} \mathrm{Cm}$ half-lives).

If we compare the time evolution of the sub-criticality level of the core, characterized by the $\mathrm{k}_{\text {eff }}$ coefficient, we observe an antagonistic evolution between the $\operatorname{MOX}(\mathrm{U} / \mathrm{Pu})$ and the minor actinide isotopes as shown in figure 2. The loss of reactivity for the $\operatorname{MOX}(\mathrm{U} / \mathrm{Pu})$ fuel is about $1.3 \%$ per year. The results show it would be possible to obtain a stable reactivity by mixing the minor actinides with plutonium and a zirconium inert matrix.

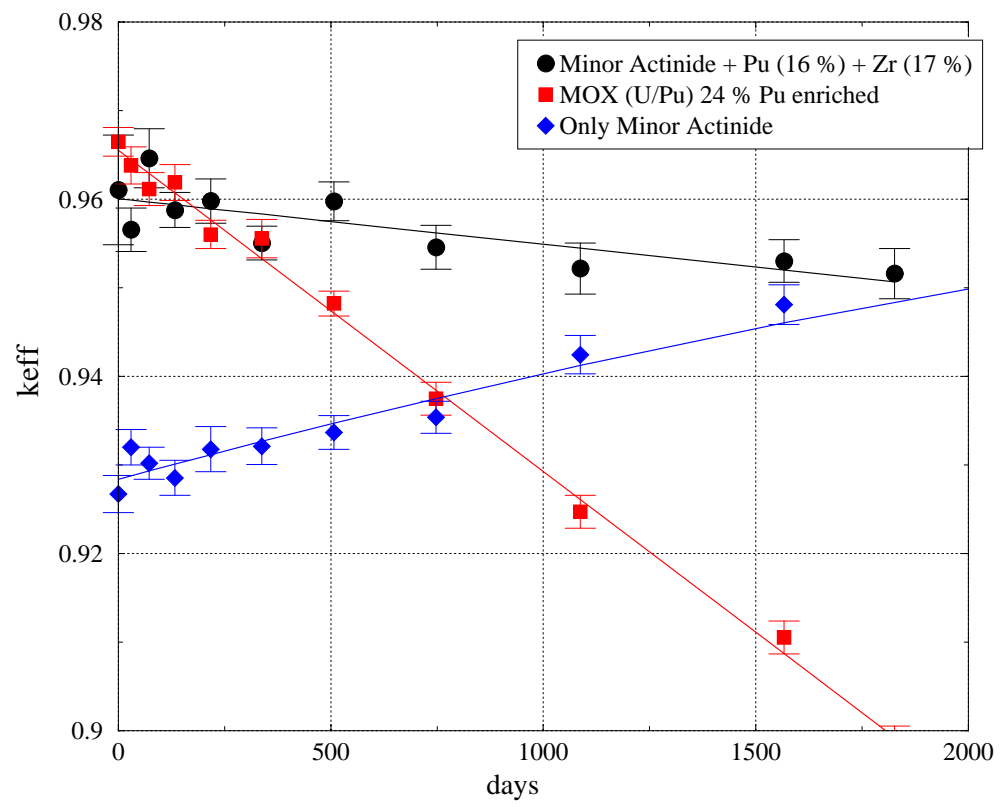

Fig. 2: Time evolution of the effective multiplication coefficient for different fuels.

The increasing reactivity due to the minor actinides is the consequence of a large proportion of americium which creates plutonium by the following capture reactions:

- ${ }^{241} \mathrm{Am}$

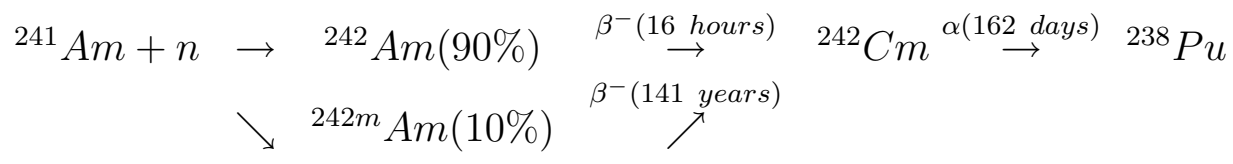

- ${ }^{243} \mathrm{Am}$

$$
{ }^{243} \mathrm{Am}+n \rightarrow{ }^{244} \mathrm{Am} \stackrel{\beta^{-}(10.1 \text { hours })}{\longrightarrow}{ }^{244} \mathrm{Cm} \stackrel{\alpha(18.1 \text { years })}{\longrightarrow}{ }^{240} \mathrm{Pu}
$$


The americium transmutation produces the fissile nuclei (in fast spectrum) ${ }^{238} \mathrm{Pu}$ and ${ }^{240} \mathrm{Pu}$ which balance the loss of ${ }^{239} \mathrm{Pu}$ by fission as shown in figure 3 .

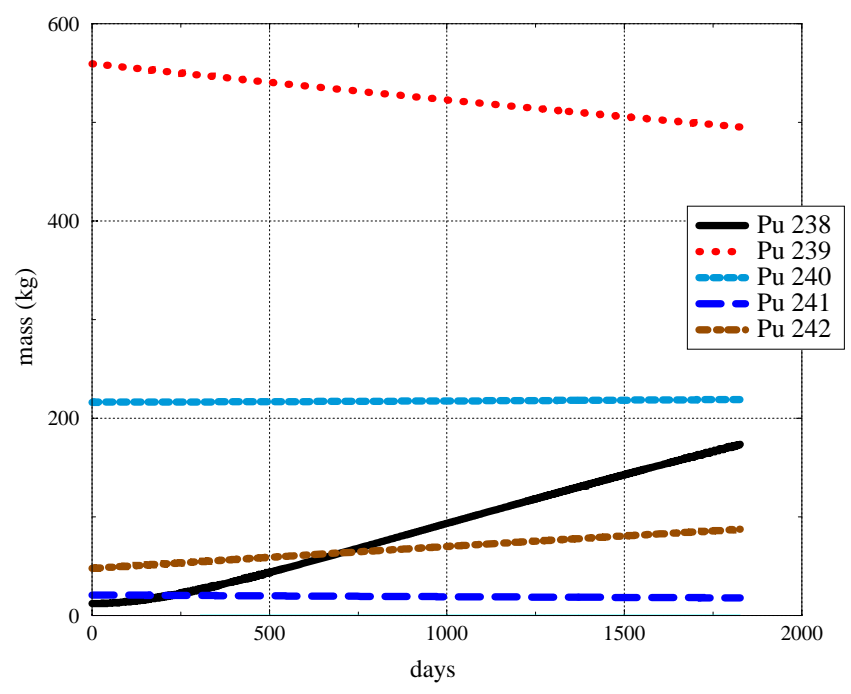

(a)

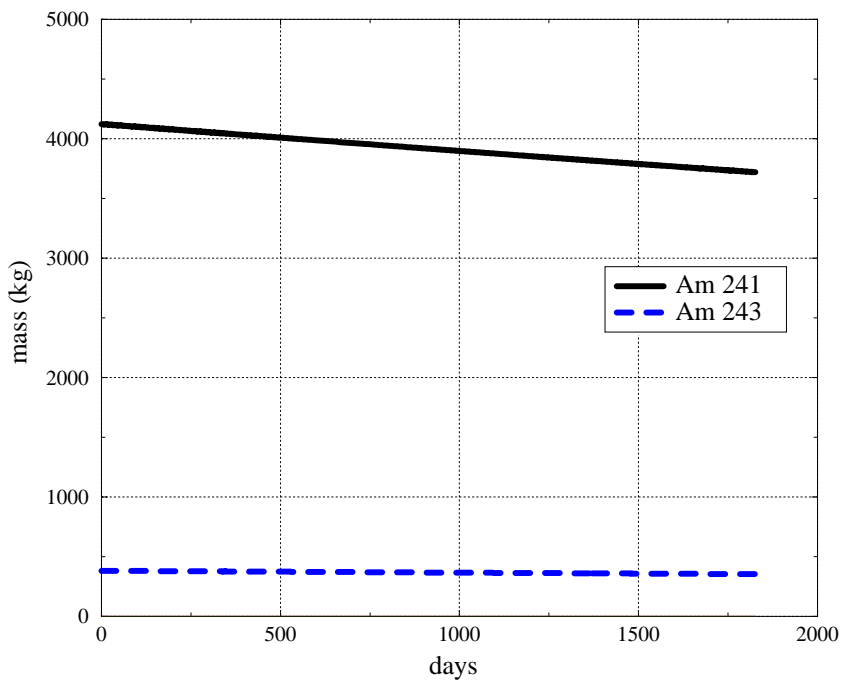

(b)

Fig. 3: Plutonium (a) and americium (b) masses as a function of reactor running time (Minor Actinides $+\mathrm{Pu}(16 \%)+\mathrm{Zr}(17 \%)$ fuel $)$.

\section{FROM XADS TO POWER ADS}

In this section, we will focus our neutronic investigations on the evolution of the shape factor and the flux when the size of the core is increased.

\subsection{The shape factor}

In order to study the extrapolation from an experimental prototype to a larger waste transmuter, we have analysed the evolution of the shape factor when the volume of the core (and consequently the thermal power) is increased, with a maximum of the linear power along the pins fixed at $375 \mathrm{~W} / \mathrm{cm}$ and a $k_{e f f}$ fixed at 0.975 . We have considered two types of target:

- the reference target defined by the Framatome company,

- a windowless target to alleviate thermo-mechanical constraints and to give additional degrees of freedom on the proton beam.

The main difference is the outside radius of the spallation target which is reduced from 29 centimeters for the reference target to 16.5 centimeters for the windowless target.

The shape factor $(F)$ is defined as the ratio of the maximum linear power $\left(P_{\max }\right)$ to the average linear power $\left(P_{\text {average }}\right)$ in the core.

$$
F=\frac{P_{\text {max }}}{P_{\text {average }}}
$$


Usually, two shape factors are defined, an axial and a radial one. The simulated active core is distributed according to a cylindrical grid which defines the cells where the flux and the deposited energy are calculated using the MCNPX code.

The shape factor increases with the size of the core. It could be problematic and could create a limitation for the efficiency of the core due to an inhomogenous temperature outflow and fuel burn-up. Figure 4 shows the radial shape factors for the two types of target. The Superphenix shape factor (1.7) is also given for comparison. Finally, the consequence of a reduced target is to reinforce the power peak and deteriorate the shape factor.

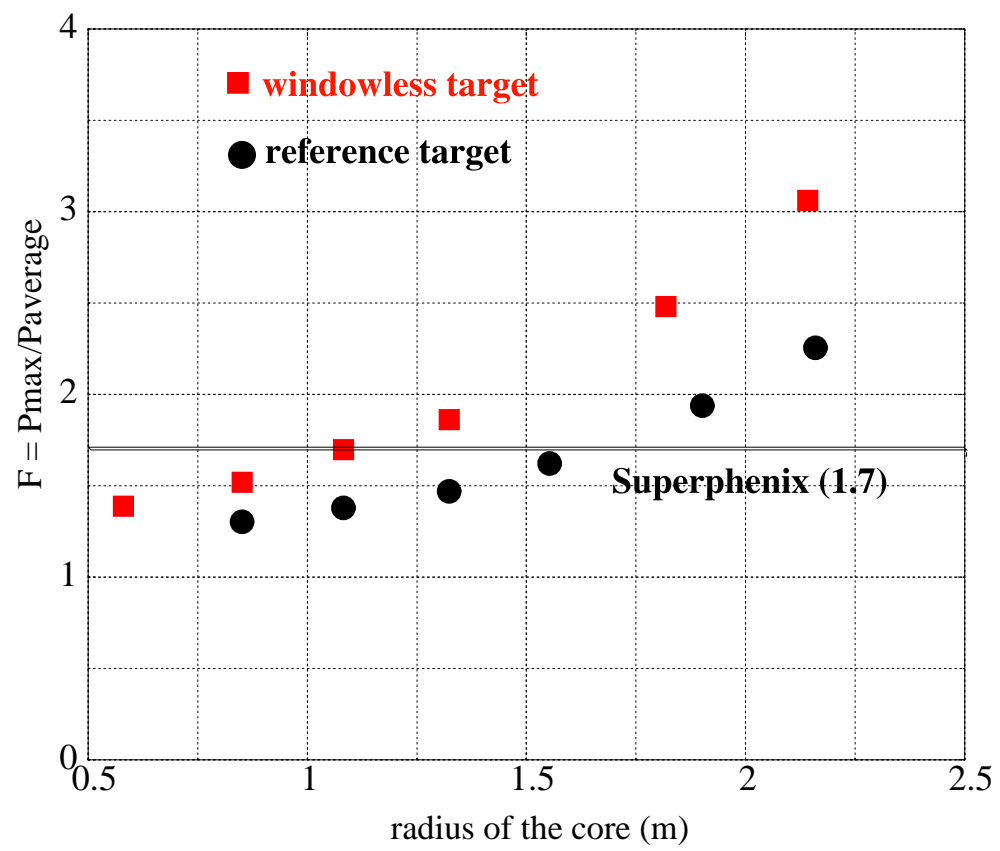

Fig. 4: Evolution of the shape factor as function of the increasing of the core sizes for the two types of targets $\left(k_{\text {eff }}=0.975\right.$ and maximum linear power $\left.=375 \mathrm{~W} / \mathrm{cm}\right)$.

\subsection{The flux and the infinite multiplication coefficient}

The evolution of the flux with the radius of the core in the median plane is shown in figure 5 . A transition appears, in the radial shape of the flux which changes from a cosine to an exponential shape.

The transition is governed by the value of the infinite multiplication coefficient which is defined as:

$$
k_{\infty}=\nu \frac{\sum^{f i s s}}{\sum^{a b s}}
$$

where $\nu, \Sigma^{\text {fiss }}$ and $\Sigma^{a b s}$ are respectively the average fission multiplicity, the macroscopic fission cross section and the macroscopic total absorption cross section. The transition is expected to appear for a $k_{\infty}$ value of one. When the size of the core is increased, the plutonium enrichment has to be decrease to keep the $k_{\text {eff }}$ value fixed. Therefore, the larger the core, the smaller the $k_{\infty}$ coefficient is. In the case of a large sub-critical reactor with reduced neutron losses, the $k_{\infty}$ coefficient could become less than one and the shape of the flux would become exponential. The evolution of the $k_{\infty}$ coefficient is shown in figure 6 . The simulated transition for the two types of targets occurs for a $k_{\infty}$ coefficient which is close to one (1.05). 


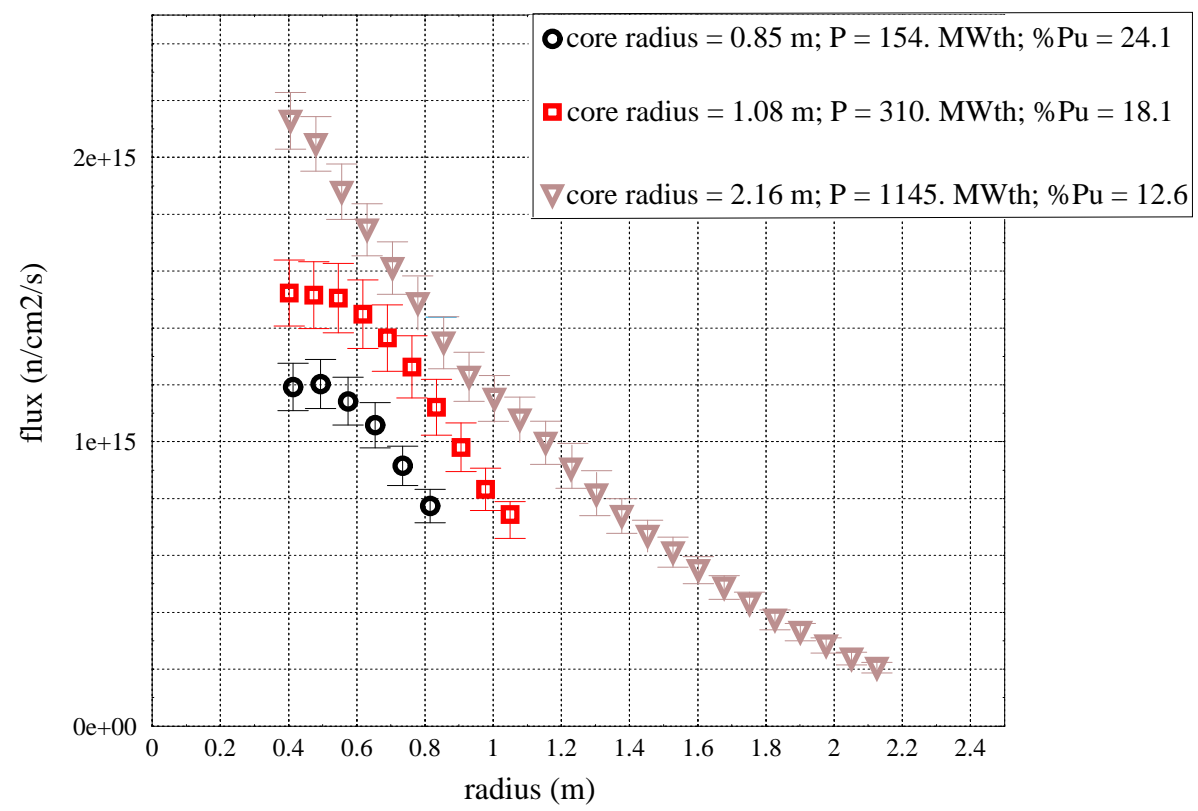

Fig. 5: Evolution of the flux in the median plan as a function of the distance from core center for different core sizes, with the reference target $\left(k_{e f f}=0.975\right.$ and maximum linear power $\left.=375 \mathrm{~W} / \mathrm{cm}\right)$.

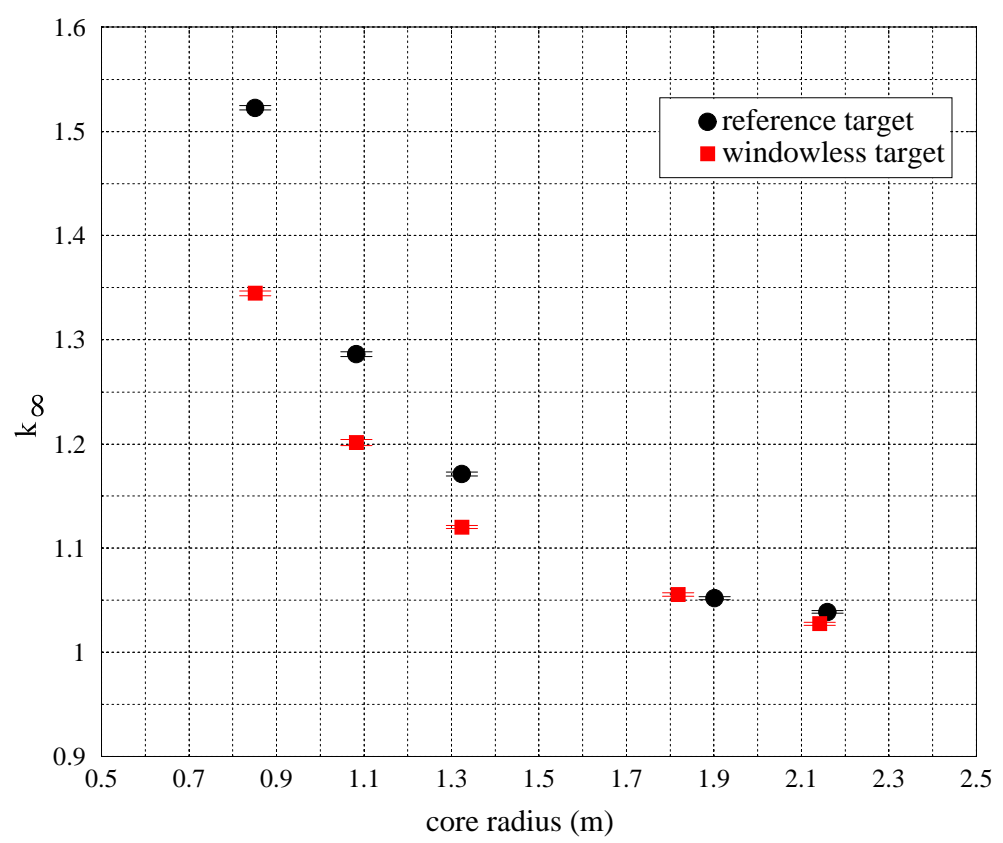

Fig. 6: $k_{\infty}$ coefficient as function of the core size $\left(k_{e f f}=0.975\right.$ and maximum linear power $=375$ $\mathrm{W} / \mathrm{cm})$. 
We examine two solutions to reduce the shape factor in the case of a large ADS whose the flux is characterized by an exponential shape:

- The first idea is to introduce a buffer zone between the spallation module and the core by removing the fuel pins in the first assemblies around the spallation module. This buffer zone induces a decrease of the flux peak and consequently improves the radial shape factor.

- The second idea is to associate to this buffer zone, a zoning of the core based on different distributions of pin densities. Precisely, we have defined three fuel zones as described in table 5.

Table 5: Characteristics of the core with three fuel zones with different densities and a buffer zone around the spallation target.

\begin{tabular}{|c|c|c|c|c|c|}
\hline Zone number & 1 & 2 & 3 & 4 & 5 \\
\hline Type & Buffer & Fuel & Fuel & Fuel & Reflector \\
\hline Filling materials & Helium & $\operatorname{MOX}(\mathrm{U} / \mathrm{Pu})$ & $\mathrm{MOX}(\mathrm{U} / \mathrm{Pu})$ & $\operatorname{MOX}(\mathrm{U} / \mathrm{Pu})$ & Steel \\
\hline $\mathrm{Pu}$ enrichment (\%) & - & 14.1 & 14.1 & 14.1 & - \\
\hline Pins per Hexagonal Tube & - & 19 & 37 & 61 & 37 \\
\hline Pin radius $(\mathrm{mm})$ & - & 7.1 & 7.1 & 7.1 & 7.1 \\
\hline$\frac{\text { Pin volume }}{\text { Hexagonal Tube volume }}(\%)$ & - & 18.2 & 35.3 & 57.5 & 35.3 \\
\hline$\frac{\text { He volume }}{\text { Hexagonal Tube volume }}(\%)$ & 100. & 63. & 50. & 30. & 50. \\
\hline
\end{tabular}

In figure 7 , we compare the radial dependence of the flux in the median plane of the core for one fuel zone with the flux obtained with three different fuel zones and a buffer zone around the spallation target. The zoning improves the shape of the flux and induces a nearly 70 percent gain on the thermal power, which increases from $464 \mathrm{MW}$ to $775 \mathrm{MW}$. Moreover, the radial shape factor in the median plane is reduced to 1.47 for the zoned core compared to 2.01 for the uniform core.

\section{THE ROLE OF ADS FOR A TRANSITION TO THE U/TH CYCLE}

Beyond the XADS scope, we present a possible use of ADS in order to start Molten Salt Reactors (MSR) based on the ${ }^{233} \mathrm{U} /{ }^{232} \mathrm{Th}$ cycle and a thermal spectrum. The use of the ${ }^{233} \mathrm{U} /{ }^{232} \mathrm{Th}$ cycle offers a valuable option for nuclear waste reduction [8]. The inventory of such a MSR is approximately 70 metric tons of thorium and 1 metric ton of uranium [9]. The ${ }^{233} \mathrm{U} /{ }^{232} \mathrm{Th}$ ratio needed to run such a MSR is $1.5 \%$. Now, we discuss the possible strategy based on ADS to produce the required fissile material.

\subsection{Initial configuration}

In these preliminary simulations, we consider a large ADS operating at a thermal power of 1000 MW. The core is composed of 360 fuel assemblies surrounded by a blanket of 120 assemblies containing ${ }^{232} \mathrm{Th}$ oxide as fertile material. The fuel is made of oxides of plutonium, minor actinides and ${ }^{232} \mathrm{Th}$. The isotopic proportions are given in table 6 . The plutonium is provided by the irradiated fuel of a 900 MWe PWR with a specific burn-up of $33 \mathrm{GWd} / \mathrm{t}$ and cooled for 50 years. 


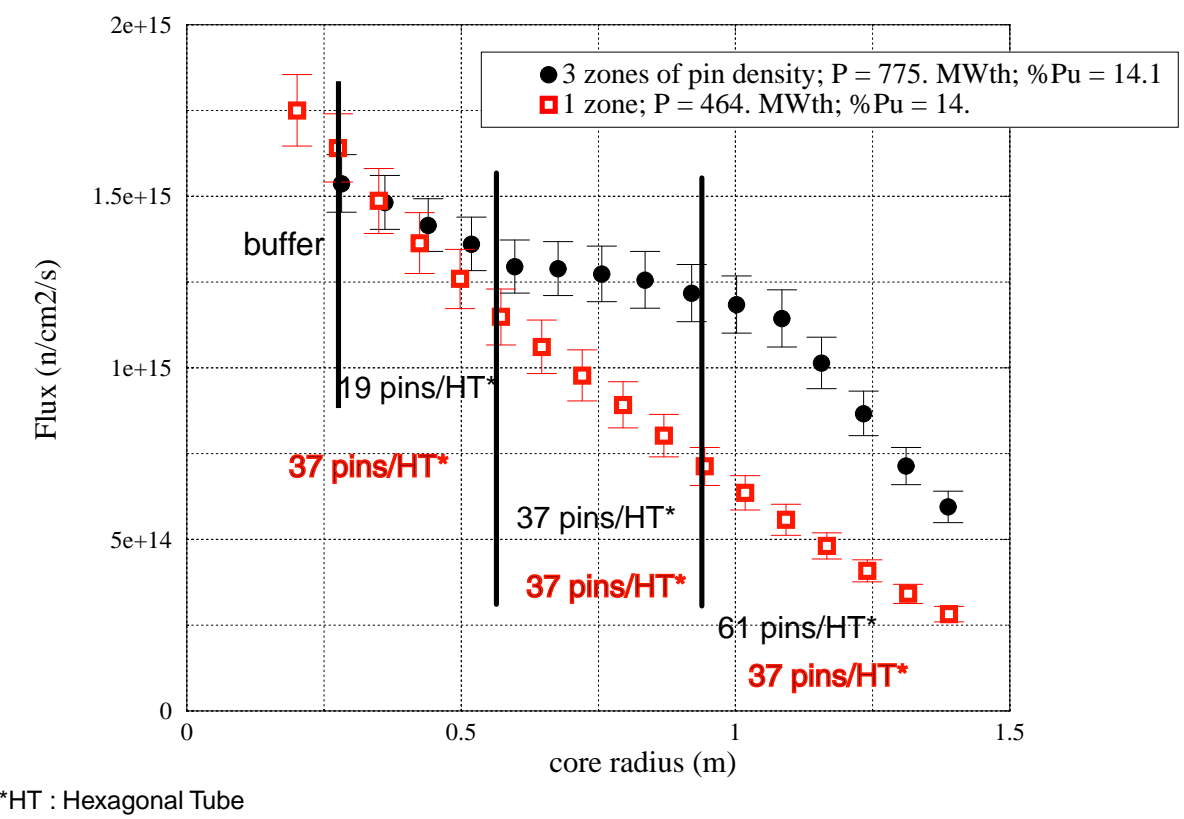

Fig. 7: Fig 7. Comparison of one fuel zone without buffer and three fuel zones of varying densities with a buffer zone around the spallation target $\left(k_{\text {eff }}=0.975\right.$ and maximum linear power $\left.=375 \mathrm{~W} / \mathrm{cm}\right)$.

Table 6: Isotopic proportions of the fuel at startup.

\begin{tabular}{|c|c|}
\hline Isotope & atomic (\%) \\
\hline${ }^{232} \mathrm{Th}$ & 82.35 \\
\hline${ }^{238} \mathrm{Pu}$ & 0.19 \\
\hline${ }^{239} \mathrm{Pu}$ & 10.11 \\
\hline${ }^{240} \mathrm{Pu}$ & 3.90 \\
\hline${ }^{241} \mathrm{Pu}$ & 0.21 \\
\hline${ }^{242} \mathrm{Pu}$ & 0.85 \\
\hline Total $\mathrm{Pu}$ & 15.26 \\
\hline${ }^{241} \mathrm{Am}$ & 2.19 \\
\hline${ }^{243} \mathrm{Am}$ & 0.19 \\
\hline Total $\mathrm{Am}$ & 2.38 \\
\hline${ }^{244} \mathrm{Cm}$ & 0.007 \\
\hline${ }^{245} \mathrm{Cm}$ & 0.003 \\
\hline Total $\mathrm{Cm}$ & 0.010 \\
\hline
\end{tabular}

Table 7: Initial elements in each zone.

\begin{tabular}{|c|c|c|c|c|c|}
\hline Zone & 1 & 2 & 3 & Blanket & Total \\
\hline Plutonium mass $(\mathrm{kg})$ & 2435 & 2435 & 2435 & 0. & 7305 \\
\hline Thorium mass $(\mathrm{kg})$ & 12728 & 12728 & 12728 & 34856 & 73040 \\
\hline Americium mass $(\mathrm{kg})$ & 381 & 381 & 381 & 0. & 1143 \\
\hline Curium mass $(\mathrm{kg})$ & 1.72 & 1.72 & 1.72 & 0. & 5.16 \\
\hline
\end{tabular}


The core is divided in three equal zones containing 120 assemblies each. The masses for each zone are given in table 7 .

\subsection{Time evolution of the fuel}

As discussed in the previous section, the magnitude of the flux is maximum near the spallation target and decreases rapidly with the radial distance. Consequently, the reaction rate on ${ }^{232} \mathrm{Th}$ depends on the radial position and hence on the core zone. The first zone around the spallation target, provides the required ${ }^{233} \mathrm{U} /{ }^{232} \mathrm{Th}$ ratio in less than one year as shown in figure 8 . We can notice the curve inflexion due to the consumption of a small amount of the new created ${ }^{233} \mathrm{U}$. The second zone reaches the required ratio in less than two years and the third zone after three years. A linear extrapolation shows that the blanket reaches the same ratio after five and a half years. As shown in figure $8, k_{e f f}$ increases due to the ${ }^{233} \mathrm{U}$ generation, the gain of reactivity being close to $5 \%$ after 5 years of irradiation without changing the fuel.

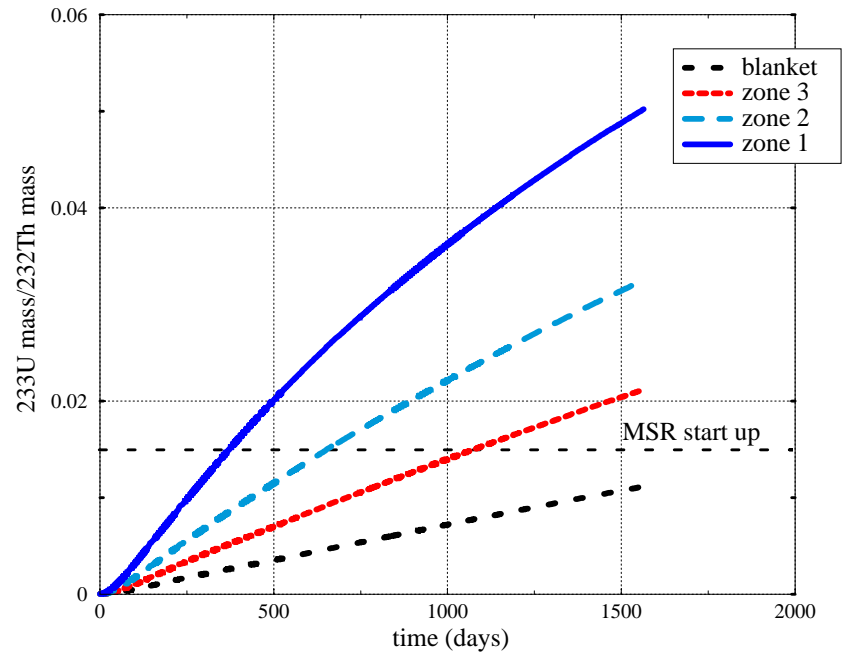

(a)

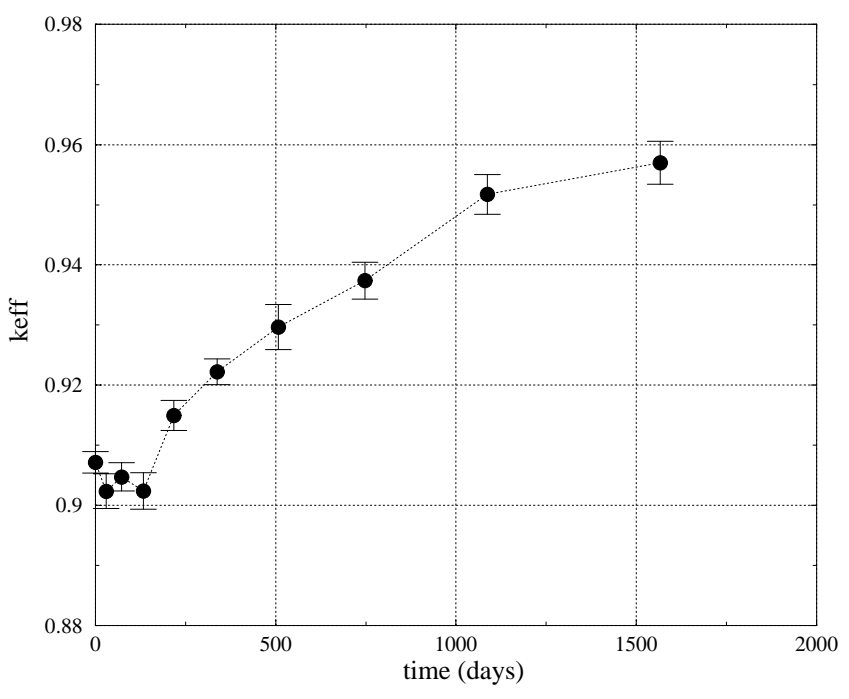

(b)

Fig. 8: Time evolution of the ${ }^{233} \mathrm{U}$ proportions in each core zone and in the blanket (a) and time evolution of $\mathrm{k}_{\text {eff }}(\mathrm{b})$.

\subsection{Optimized fuel loading}

To avoid a too large reactivity increase, we must define an optimized fuel loading procedure. The fuel composition is slightly modified in order to start with a $k_{\text {eff }}$ close to 0.95 by increasing the plutonium enrichment from $15.26 \%$ to $16.50 \%$. Each zone is discharged when the amount of ${ }^{233} \mathrm{U}$ required to start a MSR is obtained. This solution avoids the consumption of the created ${ }^{233} \mathrm{U}$ and allows a reactivity stabilization. Figure 9 shows the time evolution of the ${ }^{233} \mathrm{U}$. The first zone is discharged after a period of one year. The second zone and the first one again are dischaged after two years and so on for the other zones. With this strategy, the reactivity increase, plotted in figure 9, stays in the reasonable margin of 0.95 to 0.975 . The thermal power can then be kept constant with a proton beam intensity varying from $25 \mathrm{~mA}$ to $15 \mathrm{~mA}$ (proton beam energy : $1 \mathrm{GeV}$ ).

This fuel management provides the initial uranium/thorium inventory of two MSRs (2500 MW thermal) after five years of ADS (1000 MW thermal) operation. 


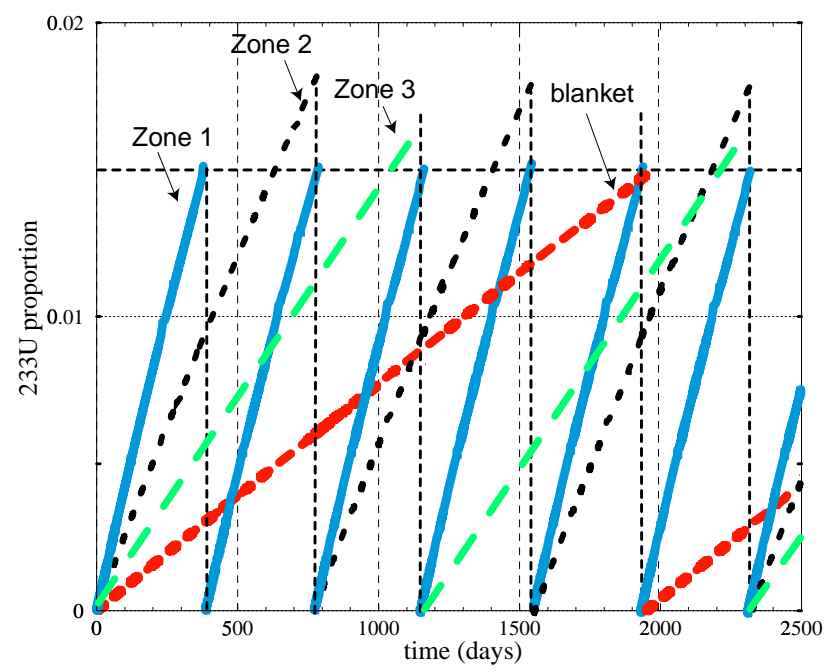

(a)

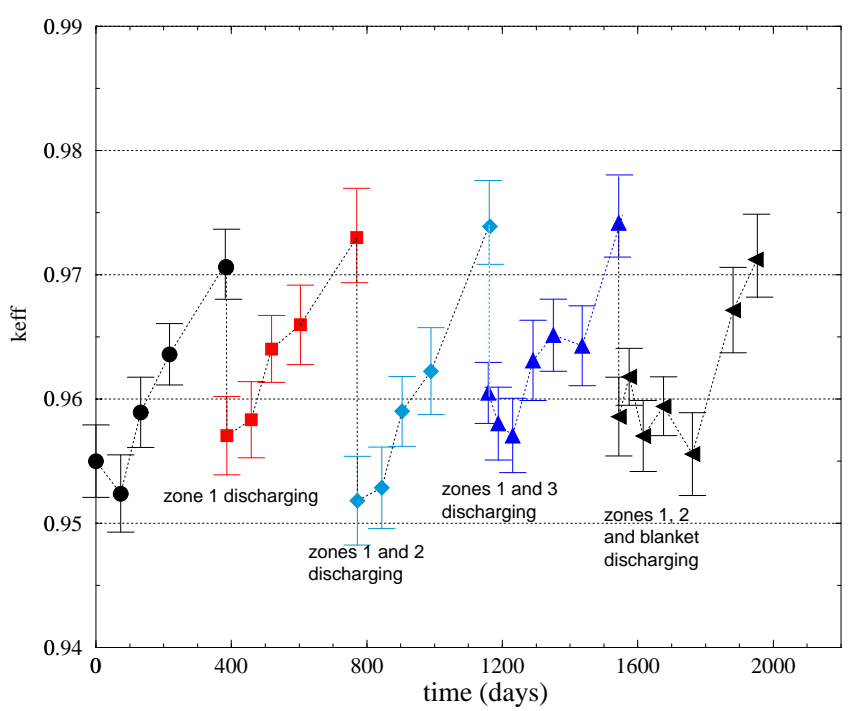

(b)

Fig. 9: Time evolution of the ${ }^{233} \mathrm{U}$ proportions in each core zone and in the blanket (a) and time evolution of $\mathrm{k}_{\text {eff }}$ (b) with optimized fuel loading.

\section{CONCLUSIONS}

In this paper, we have reported on our simulations and optimizations of the concept of XADS issued from preliminary design studies performed by Framatome ANP. We have calculated the loss of reactivity with a MOX $(\mathrm{U} / \mathrm{Pu})$ fuel and determined the composition of a minor actinide fuel in order to keep a stable sub-criticality level during a five year cycle. In a second part, we have identified some neutronic differences between a small scale prototype and a large ADS concerning the infinite multiplication coefficient, the shape factor and the flux level, to extend the demonstrator concept. A minimum shape factor being a fundamental criterion as it permits an homogeneous burn-up, we have proposed a geometric solution based on a buffer zone around the spallation target and a three zone core. Each zone has different pin densities. In this case, the extrapolation of the XADS toward a large ADS is conceivable.

Beyond the XADS scope, we have examined the possible transition toward a uranium/thorium cycle based on Molten Salt Reactors using a large ADS in order to generate the required ${ }^{233} \mathrm{U} /{ }^{232} \mathrm{Th}$ ratio. The ADS is loaded with a plutonium and minor actinides mixed oxide associated to thorium oxide. This fuel should induce a rapid transition for a thorium-based fuel cycle. The optimized fuel loading described reduces the consumption of created ${ }^{233} \mathrm{U}$, permits the generation of the initial inventory of two 2500 MWth Molten Salt Reactors by one 1000 MWth ADS in five years.

The XADS facility, which could be in operation around 2015, will provide the required flux level to test new concepts of fuel based on minor actinides and to evaluate a transition toward a thorium/uranium cycle.

Acknowledgements

We Thank E. Huffer for her valuable contribution. 


\section{References}

[1] The European Technical Working Group on Accelerator Driven System, "A European Roadmap for Developing Accelerator Driven Systems (ADS) for Nuclear Waste Incineration", April 2001.

[2] D. Hill et al, "A Roadmap for Developing ATW Technology: Systems Scenarios and Integration"”, ANL/RE-99/16.

[3] Laurie S. Waters, Editor, "MCNPX Users's Manual Version 2.1.5", TPO-E83-G-UG-X-00001 (1999).

[4] B. Carluec, "Proposal for a Gas-cooled ADS Demonstrator", ADTTA'99, Proceedings of the $3^{\text {rd }}$ International Conference on Accelerator Driven Transmutation Technologies and Applications, 7-11 june 1999, Praha (Czech Republic).

[5] R.E. Prael, H. Lichtenstein, "User Guide to LCS : The LAHET Code System", Los Alamos National Laboratory (LANL/USA), Revised September 15, 1989.

[6] H.W. Bertini, Phys. Rev. 188(1969), p 1711.

[7] NJOY 97.0, "Code System for Producing Pointwise and Multigroup Neutron and Photon Cross Sections from ENDF/B-VI Data", RSICC CODE PACKAGE PSR-368.

[8] S. David and al. "Fast Subcritical Hybrid Reactors for Energy Production: Evolution of Physical Parameters and induced Radiotoxicities", Nucl. Instr. Meth. A113 (2000) 510-530.

[9] A. Nuttin and al. "Comparison of Thorium Fuel Cycles based on Fast Spectrum Solid Fuel Subcritical Systems or Graphite-Moderated Molten Salt Reactors", International Conference on Future Nuclear Systems (GLOBAL 2001), Paris (France). 